\title{
1 A framework for modelling consumption-based energy demand and emission pathways
}

2 Alessio Mastrucci ${ }^{*, 1}$, Jihoon Min ${ }^{1}$, Arkaitz Usubiaga-Liaño ${ }^{2}$, Narasimha D. Rao ${ }^{3,1}$

$3 \quad{ }^{1}$ International Institute for Applied Systems Analysis (IIASA), Energy Program, Schlossplatz 1,

4 A-2361 Laxenburg, Austria

$5 \quad{ }^{2}$ University College London, Institute for Sustainable Resources, 14 Upper Woburn Place,

6 WC1H 0NN, London, UK

$7 \quad{ }^{3}$ Yale University, School of Forestry and Environmental Studies, 06511 New Haven, CT, United

8 States

9 ABSTRACT Energy demand in global climate scenarios is typically derived for sectors - such as

10 buildings, transportation, and industry - rather than from underlying services that could drive

11 energy use in all sectors. This limits the potential to model household consumption and lifestyles

12 as mitigation options through their impact on economy-wide energy demand. We present a

13 framework to estimate the economy-wide energy requirements and carbon emissions associated

14 with future household consumption, by linking Industrial Ecology tools and Integrated Assessment

15 Modelling (IAM). We apply the framework to assess final energy and emission pathways for

16 meeting three essential and energy-intensive dimensions of basic well-being in India: food,

17 housing and mobility. We show, for example, that nutrition-enhancing dietary changes can reduce

18 emissions by a similar amount as meeting future basic mobility in Indian cities with public

19 transportation. The relative impact of energy demand reduction measures compared to

20 decarbonization differs across these services, with housing having the lowest and food the highest.

21 This framework provides complementary insights to those obtained from IAM by considering a 
22 broader set of consumption and well-being related interventions, and illustrating trade-offs

23 between demand and supply-side options in climate stabilization scenarios.

\section{1. Introduction}

25 Meeting the goals of the Paris climate agreement will involve greenhouse gas (GHG) emission

26 reductions through a portfolio of mitigation measures, including lowering demand and resource

27 intensity, and decarbonizing the energy supply sector ${ }^{1,2}$. Global scenarios of climate stabilization,

28 such as those developed using Integrated Assessment Models (IAM), place greater emphasis on

29 supply side transformations ${ }^{3,4}$, including the energy system and land-use, than they do on

30 demand-side changes, with few exceptions ${ }^{5,6}$. Demand-side measures typically focus on direct

31 energy services in sectors (e.g. buildings, industry and transport) more than they do on

32 consumption and lifestyle changes ${ }^{4,7}$ that drive energy demand indirectly through their material

33 use. For example, changes in household demand for mobility and housing can have differing

34 impacts on energy demand depending on their material requirements for manufacturing vehicles

35 and constructing buildings, respectively. These indirect impacts are mostly overlooked by IAM.

36 As a result, global scenarios of climate mitigation are limited in their ability to represent

37 household consumption and lifestyle change through their use of materials and economy-wide

38 energy demand $d^{5,8,9}$.

39 Recent research suggests that the linkage of Industrial Ecology (IE) tools to IAMs can strengthen

40 the representation of the supply chains, material cycles and household consumption patterns in

41 climate change stabilization scenarios ${ }^{10,11}$. Previous efforts to integrate IE and energy systems

42 scenarios assess the material implications of energy supply transformations to meet climate

43 targets ${ }^{11-13}$. IE methods, such as Life Cycle Assessment (LCA) and Environmentally Extended 
44 Input-Output (EEIO) analysis, connect production and consumption activities to their associated

45 energy and resource use by mapping supply chains. Integrating IE methods and energy scenarios

46 can enable an assessment of the trade-offs and synergies between production, consumption,

47 material requirements and energy use of different climate change mitigation options.

48 IE studies that evaluate demand-side emission reduction potential offer a range of flexibility to

49 represent future energy system transformations. Traditional LCA methods were designed to

50 assess specific products and processes. As a result, they tend to be static in time and oriented to a

51 micro-scale ${ }^{8,14}$ More recently, several studies assess future environmental changes across a

52 broader scope of economic activity. However, often LCA studies neglect future changes in the

53 energy system ${ }^{15-17}$. Other recent hybrid LCA-IO studies do include impacts of energy system

54 changes, but their main scope of analysis is limited to the electricity sector ${ }^{18}$ or specific end-use

55 services, such as transport ${ }^{19}$, efficient lighting ${ }^{20}$, and energy management systems ${ }^{21}$. On the

56 other hand, EEIO analysis has been widely used to assess historical indirect energy and

57 emissions from sectors based on consumption-based accounting principles ${ }^{22-27}$. Recent studies

58 attempt to project EEIO models into the future based on a given set of technology and climate

59 scenarios and simplified projections of changes in household final demand structure ${ }^{28,29}$. This

60 dependence on specific, and most likely different, scenarios of energy system transformations

61 makes these studies difficult to compare to each other or extend to other demand categories and

62 IAM scenarios of energy system transformation.

63 Despite these efforts, studies that project economy-wide household service-driven energy and

64 emissions pathways are largely missing. In a previous work ${ }^{30}$, we proposed the Service-Driven

65 Energy Accounting model (SEAM) to calculate products' embodied final energy demand, which

66 aggregates relevant direct energy demand in all the traditional sectors involved in the product 
67 supply chain. In this paper, we extend the SEAM framework to develop emissions pathways for

68 household services by combining estimates of final embodied energy demand and emissions of

69 products with IAM scenarios of decarbonization. This framework enables a comparison of the

70 mitigation potential of well-being driven interventions to reduce consumption across different

71 product groups and at different points in the supply chain to the more traditional demand

72 reduction and supply-side options in the energy system obtained from IAMs. This approach of

73 integrating consumption with IE and IAM also allows us to differentiate energy and emissions

74 associated with building new infrastructure and that associated with providing services over

75 existing infrastructure. For instance, one could compare the mitigation potential of, such as

76 behavioral change in building space cooling compared to electrification in the mobility sector.

77 We apply this model to illustrate energy and emissions pathways for bridging gaps in three key

78 services of "decent living standards" (DLS) in India ${ }^{31}$ : housing, mobility, and food. We generate

79 scenarios to bridge existing service gaps, including building the necessary underlying

80 infrastructure. We explicitly model influences of behavioral and technological changes on energy

81 demand on the one hand, and future changes in energy supply on the emissions pathways, on the

82 other, to illustrate their relative contribution to decarbonization of basic needs.

\section{2. Materials and methods}

84 Our generic framework includes three steps (Fig.1). First, we estimate the demand level for

85 residential (square-meters of floor surface per housing type), mobility ( $\mathrm{p}-\mathrm{km}$ per transportation

86 mode) and other services such as food (expenditure level) according to previously identified

87 standards ${ }^{32-34}$. Second, we calculate direct and indirect final energy demand associated with

88 materials and services. For this, we use IE tools, as appropriate, to estimate the indirect energy 
89 intensities per service unit: LCA for services with easily definable material requirements, such as

90 buildings and mobility; and EEIO analysis for the remaining services whose material use is more

91 diffused through the economy. We then build scenarios which model current practices as well as

92 low-carbon technologies, consider their future penetration and include material efficiency

93 improvements. We estimate the total final energy requirements by multiplying the demand of the

94 service in each scenario by the respective energy intensities. Third, we calculate emissions

95 pathways under different scenarios of climate policy, including a reference and climate

96 stabilization at $1.5^{\circ} \mathrm{C}$, using carbon intensities of fuels from IAM scenarios.

97 The following sections describe the generic LCA and EEIO methods we developed to estimate

98 the indirect final energy intensities of services, the exemplary application to DLS scenarios, and

99 the three modelled end-use sectors (housing, mobility, and food).

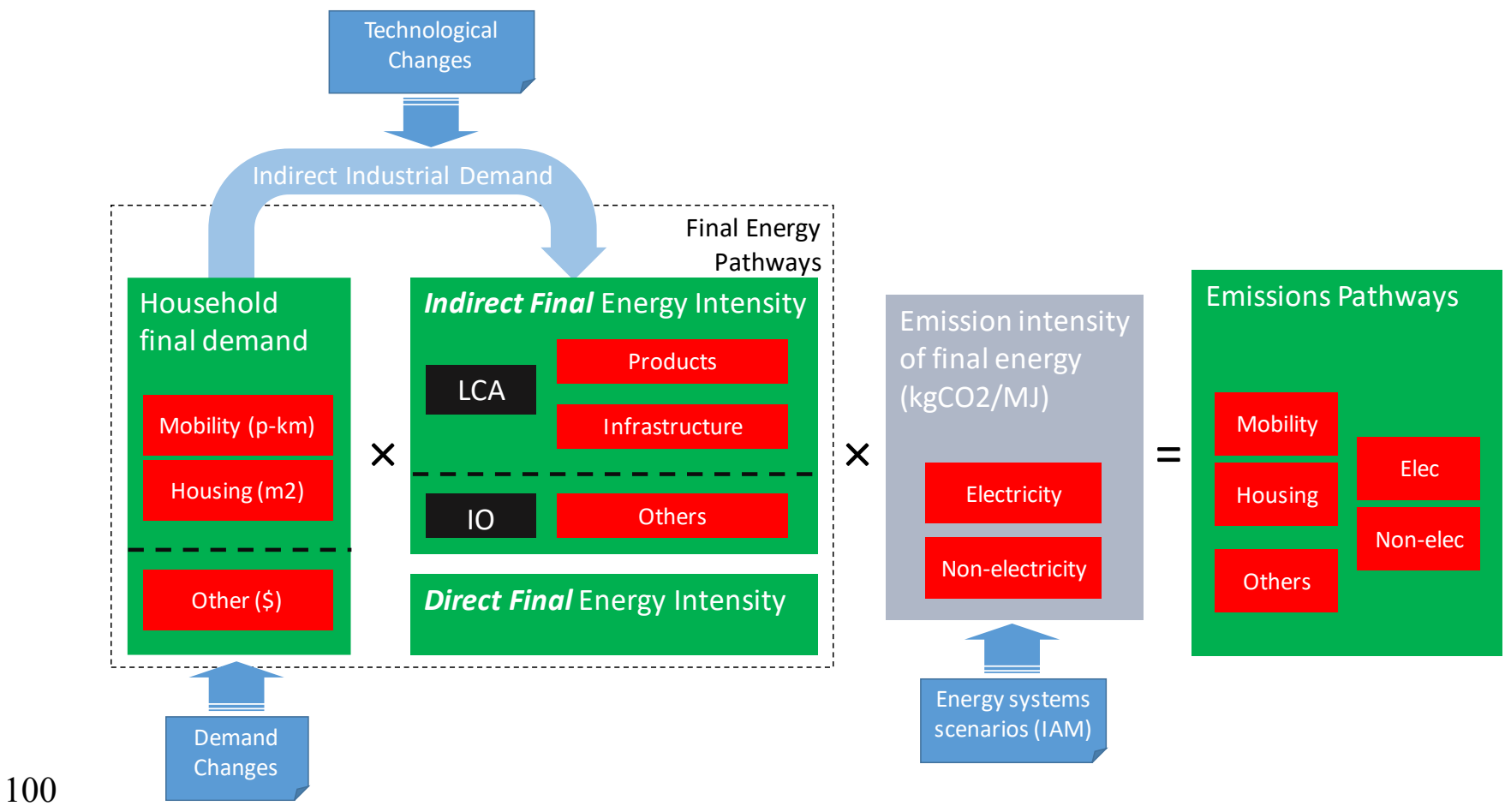

101 Figure 1. Overview of the methods for final energy and emissions pathways. 


\subsection{Energy intensities calculation}

104 We use process-based LCA to link services to their indirect energy requirements and develop 105 energy demand pathways in final energy terms. This differs from traditional LCA, where final 106 energy is disregarded in favor of primary energy for assessing depletion of energy resources. To

107 our best knowledge, only two studies in literature used a similar approach and estimated energy 108 coefficients from LCA for assessing power sector scenarios ${ }^{8,35}$. Our application differs in that it

109 focuses on end-use services and linkages with induced final energy demand.

110 We derive final energy demand by calculating ratios of final to primary energy for specific

111 products or processes. As first approximation, we assume that the difference between primary

112 and final energy is the conversion and delivery losses for electricity production and distribution

113 respectively, and that final energy equals primary energy (that is, conversion losses are assumed

114 negligible) for energy carriers other than electricity ${ }^{36}$. Products' and processes' relative final

115 energy intensity differ from their relative primary energy intensity based on the share of

116 electricity - and in turn its efficiency of conversion.

117 The final electricity embodied in each product of interest is estimated by using the technology

118 matrix $^{37}$, which maps inflows and outflows of commodities from processes. The activities

119 supplying electricity for end uses are filtered along the supply chain via the technology matrix

120 and the associated electricity use summed up (see Supplementary Information). We then run the

121 impact assessment and use the indicator Cumulative Energy Demand (CED) ${ }^{38}$ to calculate

122 embodied primary energy, which as explained above, for non-electricity products is assumed to

123 be the same as final energy use. The embodied final energy related to other fuels is calculated as 
124 the difference between total CED and CED of the electricity supply activities associated with a

125 given product. We finally obtain two coefficients to customize results to the local context for

126 each product: the electricity share of final energy; and the ratio of final to primary energy (see

127 Supplementary Information). We use Brightway $2^{39}$ to process data from the database

128 Ecoinvent ${ }^{40}$ (v3.3 cut-off).

131 We use the standard EEIO equations ${ }^{41}$ to calculate the indirect final energy intensities of 200

132 products of EXIOBASE3 - a widely used environmentally extended global multi-regional input-

133 output (EE-GMRIO) database. The key difference with previous studies that use EXIOBASE is

134 that we employ a final energy extension extracted from net energy use (NEU) accounts

135 specifically developed for this analysis. NEU refers to the end use energy of energy products

136 minus exports plus all energy losses (i.e. during extraction, transformation, storage and

137 distribution $)^{42}$. The NEU accounts built for this paper are largely based on the approach used in

138 Stadler et al. ${ }^{43}$ and documented in Usubiaga-Liaño et al. ${ }^{44}$ (see Supplementary Information). In

139 short, the extended energy balances of the International Energy Agency ${ }^{45,46}$ are first transformed

140 from the territory to the residence principle to resolve accounting differences (see Usubiaga et

$141 \mathrm{al} .{ }^{47}$ for more details). From the resulting dataset we calculate the energy product-specific NEU

142 and only allocate the final energy consumption to EXIOBASE products and final consumers

143 using the same allocation approach as in Stadler et $\mathrm{al}^{43}$, which results in a final energy use

144 extension. Then, indirect final energy intensities are derived from this extension using the

145 standard demand-pull IO model. The intensities by EXIOBASE product are then mapped to 
146 matching COICOP (Classification of Individual Consumption According to Purpose) categories

147 by the approach given in Min and $\mathrm{Rao}^{48}$. For the aggregate food energy intensity, we weight-

148 average the final energy intensities by COICOP category with the monetary share of different

149 food items in the diets considered in the DLS scenarios. While the intensities for each of

150 COICOP categories are assumed constant over time (i.e. no changes in production processes),

151 the aggregate intensities change over time due to the changes in diet composition in different

152 scenarios.

\subsection{Application to DLS scenarios}

154 Previous work has focused on identifying a set of components defining DLS ${ }^{31}$. Here, we

155 illustrate the merits of the proposed methods by developing final energy and emissions pathways

156 for three key end-use services in DLS scenarios: housing, mobility and food. Energy

157 requirements are divided in two components: the operational energy associated with the

158 provision of goods and services (including direct energy for housing and mobility, and indirect

159 energy for food production); and the construction energy necessary to build the underlying

160 infrastructure (housing construction, public transport infrastructure, and vehicles production).

161 We do not include other food-related energy used directly in households such as cooking or

162 refrigeration. India provides a remarkable case study for the important gaps in access to decent

163 living and opportunities for limiting the energy and GHG emissions required to fill such gaps.

164 We present two demand scenarios for 2050, where DLS gaps are filled by 2030, in accordance

165 with SDGs targets ${ }^{49}$. These gaps include access to decent housing, motorized transportation and

166 adequate nutrition (see below). In the reference (REF) scenario, requirements are fulfilled with

167 current prevailing development strategies and technologies. The low-carbon technology (LCT) 
168 scenario includes exemplary emissions-saving development strategies, such as energy-efficient

169 design for buildings, public transportation and diet changes. A variant of the LCT scenario for

170 mobility (LCT*) evaluates the complete electrification of public transportation by 2030 .

171 In a second step, the scenarios above are further developed by incorporating potential changes

172 in energy supply system that lead to a decrease of emission intensities for supplying electricity

173 and other non-electric fuels (separately for industry and transportation) from two representative

174 climate policy scenarios. One is no energy policy scenario (PS1), where we assume no policy

175 changes from status quo, and thus the average emission intensities of India in 2015 are kept

176 constant until $2050\left(0.235 \mathrm{kgCO}_{2} / \mathrm{MJ}\right.$ for electricity, $0.055 \mathrm{kgCO}_{2} / \mathrm{MJ}$ for non-electric fuels in

177 industry, $0.072 \mathrm{kgCO}_{2} / \mathrm{MJ}$ for non-electric fuels in transportation). The other (PS2) is an

178 ambitious policy scenario, which represents the efforts needed to have $66 \%$ chance of limiting

179 the global temperature increase to under $1.5^{\circ} \mathrm{C}$ in $2100^{50}$ (emission intensities in 2050 are -0.002

$180 \mathrm{kgCO}_{2} / \mathrm{MJ}$ for electricity, $0.007 \mathrm{kgCO}_{2} / \mathrm{MJ}$ for non-electric fuels in industry, $0.044 \mathrm{kgCO}_{2} / \mathrm{MJ}$

181 for non-electric fuels in transportation). We include non-energy emissions for cement in housing

182 construction and methane in food production (see Supplementary Information for more details on

183 emissions intensities). From this, we can separately investigate the relative contribution of

184 demand- and supply-side policies in reducing emissions growth.

$185 \quad$ Housing

186 The DLS for housing include minimum floor surface $\left(10 \mathrm{~m}^{2}\right.$ per person, minimum $30 \mathrm{~m}^{2}$ up to

1873 persons), permanent construction materials and a suitable level of thermal comfort ${ }^{31,33}$. We

188 represent rural and urban housing by a single-story and a multi-story archetype respectively, 189 reflecting prevailing construction practices ${ }^{51-55}$, and focus on construction and space cooling- 
190 heating only (appliances and other end uses are not considered). We rely on previous studies for

191 the estimation of energy requirements for space cooling and heating under the five different

192 climatic zones in India (see Supplementary Information). In the REF scenario, we keep the

193 characteristics of new housing unaltered over time. In the LCT scenario, we incorporate energy-

194 efficient building design that reduce both construction and operational energy requirements ${ }^{51}$ and

195 material efficiency improvements for steel and other construction materials.

196 The extension of the housing stock is estimated for every time step based on the housing

197 demand, driven by population growth and the housing gap. Currently, India has a housing gap of

19850 million units ${ }^{56}$, due to poor construction quality, overcrowding and homeless population. We

199 assume universal access to decent homes by 2030 according to SDG11 (Sustainable cities and

200 communities). The yearly building turnover rate is fixed at $2 \%$ of the total stock, considering a

201 service life of 50 years ${ }^{55,57,58}$.

202 Mobility

203 Normative requirements for mobility include access to motorized public and private

204 transportation. In previous work, we adopt a minimum mobility requirement of 10,000 p-km,

205 triangulated from a number of data points on minimum travel distance in dense industrialized

206 countries $^{32,59}$. In the REF scenario, we keep transportation mode shares constant at present levels.

207 In the LCT scenario, all future incremental mobility demand in cities is met by public transport,

208 which has lower energy intensity per p-km and congestion reduction benefits ${ }^{60}$, while the mode

209 shares are maintained constant in rural areas. The fuel mix of the fleet is considered as constant

210 over time in both scenarios. The construction energy for public transportation infrastructure is 
211 estimated based on previous studies ${ }^{61}$, construction of roads is not included. We use a stock

212 model for LDVs production activities over time (see Supplementary Information).

213 Food

214 For food, in the REF scenario, nutritional requirements (represented by dietary reference

215 intakes (DRI)) are met in 2030 based on present diets ${ }^{62}$. The LCT scenario represents emissions-

216 minimizing diets that also meet the DRIs, but only by 2050 , to allow for the time associated with

217 the implied dietary shifts. Note that the calorie requirement is constant over time, but its

218 composition varies with the scenarios. In particular, the calorie share of methane-intensive rice

219 reduces from $31 \%$ in REF to $5.6 \%$ in LCT due to its substitution by other grains such as wheat,

220 potato, corn, bajra, etc.

\section{3. Results and Discussion}

222 This analysis enables a comparison of the embodied energy intensities of basic services enjoyed

223 by households in an economy, independent of their economic value and energy supply. We discuss

224 the features and benefits of these types of results in three steps: we first compare these energy

225 intensities to conventional approaches that present primary energy intensities; we then compare

226 the construction and operational energy requirements of these services; lastly, we discuss the

227 relative mitigation potential across services and across the energy supply chain (i.e. demand

228 reduction vs decarbonization). We discuss the empirical findings as well, but primarily as a vehicle

229 to illustrate the methodological contribution.

\subsection{Final vs primary energy intensities}


231 Figure 2 compares the final and primary energy intensities for different housing types (new

232 construction) and transport modes (panel A) and the averages for all the services in both REF

233 and LCT scenarios in 2050 with no changes in the current energy system (panel B). We separate

234 the energy associated with electricity and the rest, in order to illustrate their difference in

235 decarbonization potential.
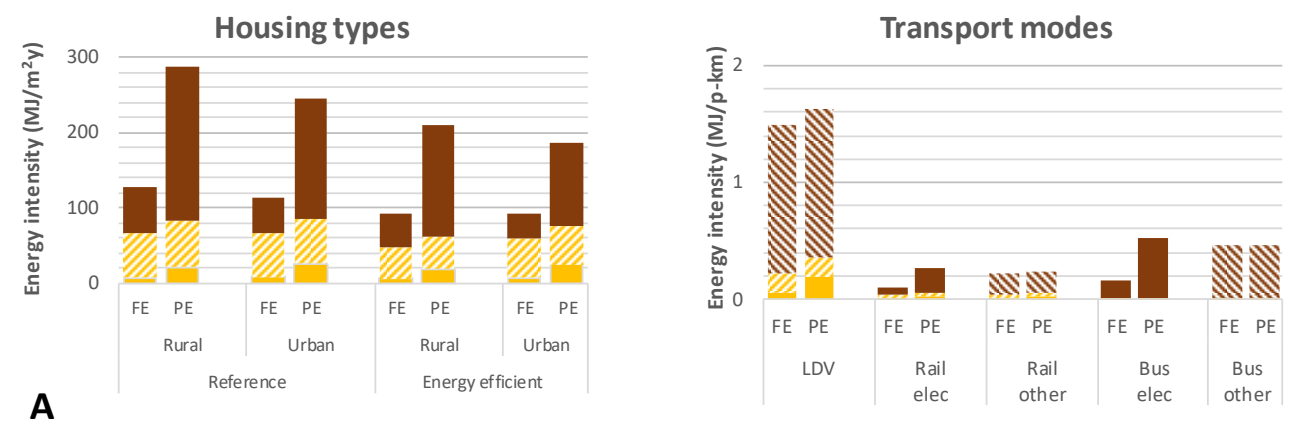

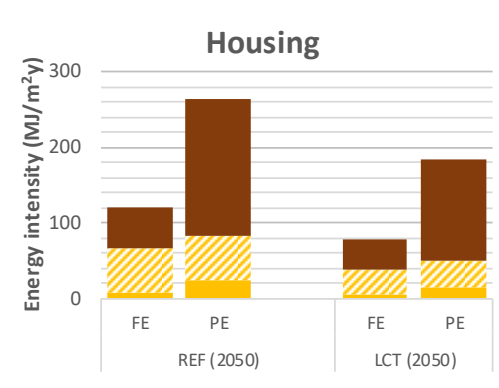

B

236

237

238 (new construction) and transport modes. Panel B - Average FE and PE for housing, mobility and

239 food in India in the reference (REF) and low-carbon technologies (LCT) scenarios in 2050 with

240 no changes in the current energy system (panel B). Breakdown of FE and PE shown into

241 construction (CON) and operation (OP) energy, and attributable to electricity use (elec) and other

242 fuels (non.elec). See Supplementary Information for more details.

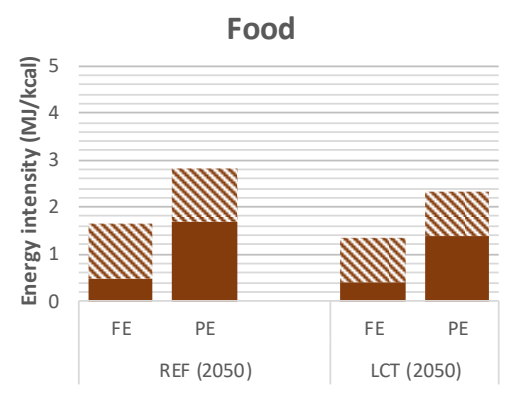

$m$ CON elec 2 CON non.elec $\mathbf{m}$ OP elec $\mathbf{x}$ OP non-elec

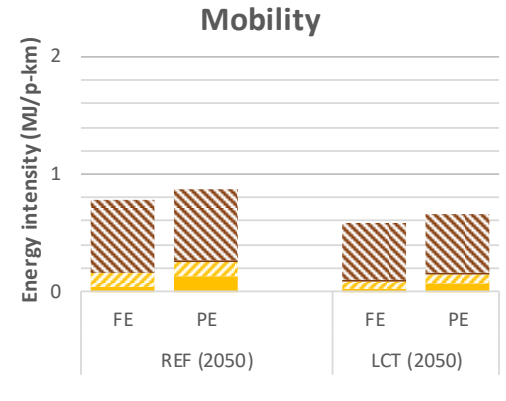

$$
\text { . }
$$


243 Due to the high conversion losses in electricity production, the energy demand when portrayed 244 in terms of primary energy shows a misleading dominance of use. Electricity use for cooling, for 245 instance, comprises less than half of the life-cycle energy demand for buildings, but in primary

246 energy terms its contribution is around two-thirds. This share is even less in urban areas,

247 because multi-storey buildings are more efficient per unit of floorspace. Viewing energy demand 248 in final energy terms better informs the leverage efficiency improvements in operation can have 249 on overall energy use relative to upstream changes in building construction (e.g. cement 250 production) or electricity production. Furthermore, with this information one can assess the 251 impact on energy demand from just the structure of growth (e.g. urbanization), in this case, 252 through its effect on building stock. For mobility, electricity comprises a greater share of 253 construction energy demand (25 percent) than in buildings (9-12 percent) because of the 254 electricity intensity of steel, which in turn comprises a higher share of materials in vehicles than 255 in buildings. For food, a relatively small share of electricity in overall final energy shows that 256 efficiency improvements in typical electricity consumption along the supply chain of food (e.g. 257 storage, refrigeration, packaging) will have a limited role under the current practice. The relative 258 proportion between reductions in final energy terms and in primary energy terms, for a specific 259 service, is therefore influenced considerably by the share of electricity versus other fuels for the 260 adopted measures.

261 Having service-driven energy intensities also enables complementary scenario analysis, in that 262 the relative effects of interventions at different points in the supply chain can be compared 263 (Figure 2-B). For instance, a comparison of the average energy intensities of services in the REF 264 and LCT scenarios in 2050 reveals that the relative extent of energy demand reduction from 265 different interventions in the three services: 35 percent for housing from improved design and 
266 low-embodied energy materials; 24 percent for mobility from deeper penetration of public 267 transit, and 17 percent for food from diet shifts.

\subsection{Final energy demand of services}

269 Combining energy intensities with service levels associated with basic needs, we can compare

270 the relative contribution of these services to aggregate energy demand. We see from Figure 3

271 that, by far, the operational energy for road vehicles (which is primarily diesel) dominates energy

272 demand for basic needs. This demand is about a factor of 2.5 greater than the next largest

273 category, the non-electric fuel demand in the supply chain to construct the vehicles. In the

274 building sector, the immediate demand is for bridging the existing housing deficit, but with time

275 the share of new homes to meet population growth in urban areas and building turnover remains

276 relatively constant. With this kind of decomposition, we are able to estimate the change in

277 energy demand for rural and urban homes from social policies that affect population growth,

278 such as those associated with women's education and associated changes in fertility, in addition

279 to energy policies. Introducing more energy-efficient buildings (LCT scenario) has an immediate

280 effect on reducing the construction energy for filling the housing gap. However, the reduction in

281 operative energy at stock level is slower due to relatively long building turnover cycles for

282 replacing the current stock.

283 We also see that a shift in mode shares towards public transit in cities (LCT scenario) without

284 any other changes can reduce mobility-related energy demand by over 25 percent. This shift also

285 reduces the construction energy for the fewer needed vehicles. Full electrification of public

286 transport (LCT* scenario) further reduces final energy by an additional 20 percent - an all-

287 electric bus fleet demands a third of the final energy demand of a conventional fleet. In contrast, 
288 shifting construction practices to adopt more efficient building materials produces a higher

289 percentage reduction in building construction energy, but the aggregate impact is insignificant

290 compared to the shift in transport modes, also due to the slower uptake of new buildings. This

291 kind of comparison of impacts across services and at different points in the energy supply chain

292 is made possible by this service-driven model for indirect energy demand.

293 In comparison to buildings and mobility, energy use for food is relatively invariant across the 294 two scenarios. This is because food emissions in India are dominated by methane from rice, 295 while energy use is dominated by fertilizers ${ }^{63}$, which vary comparatively less across grains. As a

296 result, emissions-reducing diets reduce rice use and methane, but only marginally reduce 297 fertilizer and energy use. 

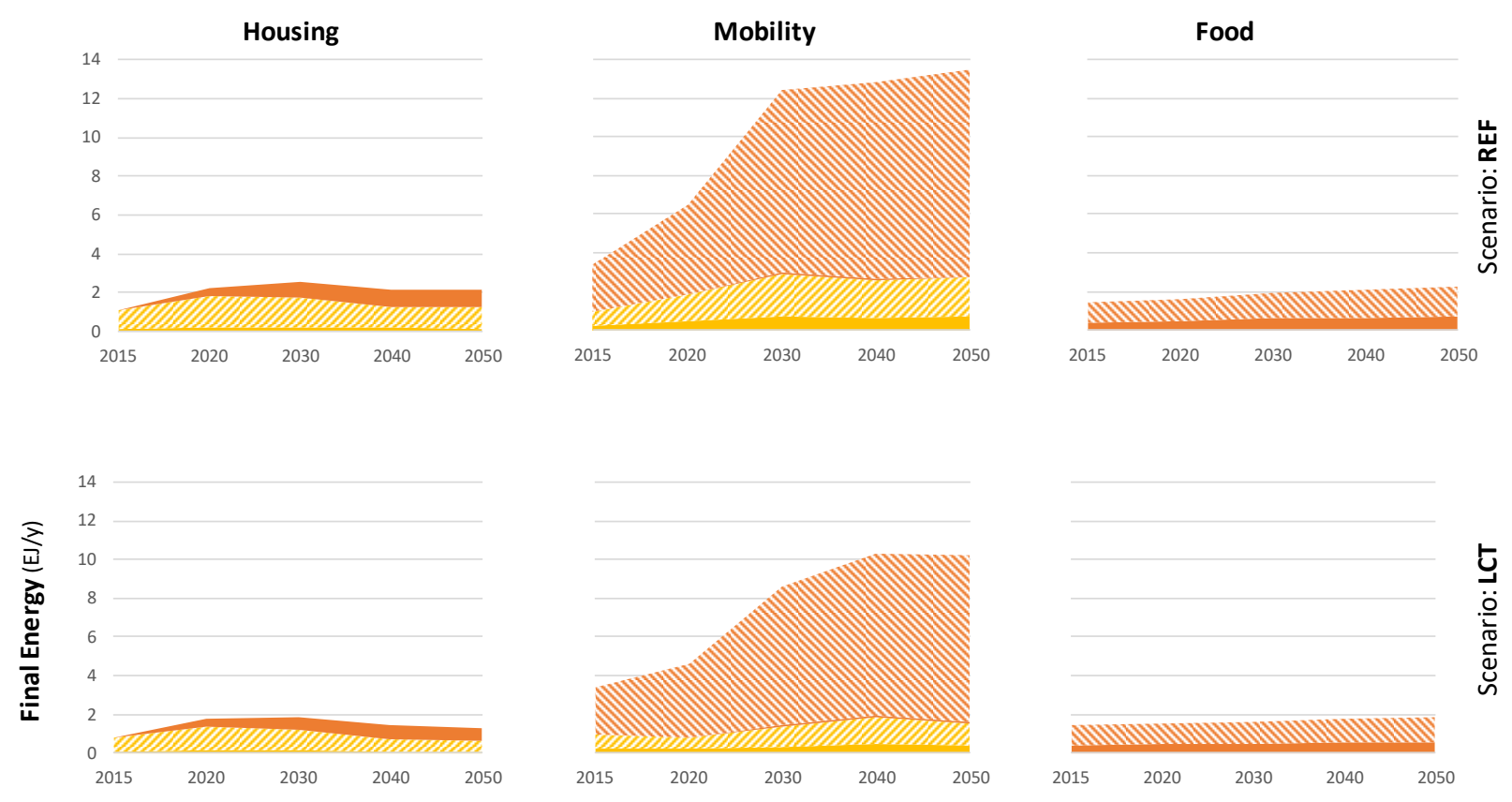

Legend
NOP non.elec
$\square$ OP elec
CON non.elec
$\square$ CON elec

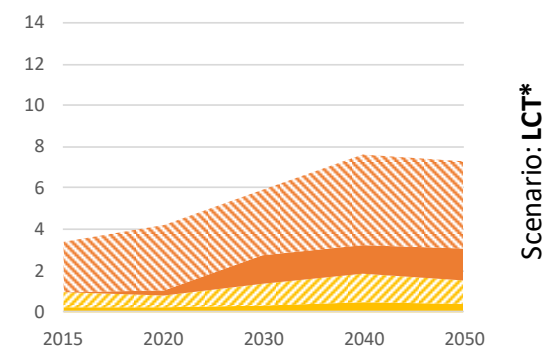

299 Figure 3. Final energy pathways for DLS scenarios for housing, mobility, and food in India.

300 Demand side scenarios: reference (REF), low-carbon technologies (LCT), and low-carbon

301 technology with full public transport electrification (LCT*). Breakdown by construction (CON)

302 and operation (OP) energy and by electricity (elec) and other fuels (non.elec).

\subsection{Identifying mitigation priorities}

305 We apply carbon intensities of fuels to meet the above energy demand projections from two

306 decarbonization futures at two extremes of ambition, one with current climate policy frozen (PS1),

307 and the other achieving the $1.5^{\circ} \mathrm{C}$ target (PS2). In doing so, we illustrate the comparative mitigation 
308 potential from different mitigation measures from the supply and demand side, and include

309 changes in how basic needs are met without reducing wellbeing.

310 First, note that the absolute emissions levels of the three demand categories are comparable (Figure

3114 ), even though their final energy demand differs widely (Figure 3), with mobility dominating the

312 other services by over a factor of five. In the case of food, this is largely because of the dominance

313 of non-energy emissions from rice cultivation in food-related emissions. For buildings, this is in

314 part because of non-energy emissions from cement production and the relatively high share of

315 electricity in final energy, which has a high carbon intensity due to coal.

316 The relative impact of decarbonization and energy demand reduction differs for each service. As

317 discussed earlier, demand-side measures have a greater potential to reduce energy demand with

318 mobility compared to housing, which propagate to their respective emissions reductions potential

319 (straight orange lines in Figure 4). For the case of food, although energy demand doesn't reduce

320 from demand-side diet shifts, significant emissions can be reduced due to the avoidance of methane

321 emissions from shifts away from rice. This reduction exceeds the potential for emissions

322 reductions from the energy demand reduction in the other two services.

323 Assuming, hypothetically, that India decarbonizes the energy sector in accordance with a $1.5^{\circ} \mathrm{C}$,

324 in absence of demand changes (dotted blue lines in Figure 4), the potential emissions reductions

325 by 2050 are on the order of 55 and 80 percent for housing and mobility respectively, but far less

326 for food, as expected, due to high non-energy emissions. Notably, for food, diet changes produce

327 comparable emissions reductions as does this ambitious shift to decarbonized fuel.

328 In housing, because of the dominance of electricity in energy demand, emissions reduction from

329 decarbonizing electricity production dominates overall mitigation potential, which is comparable 
330 in both $1.5^{\circ} \mathrm{C}$ scenarios, with and without demand reduction. What emissions remain in both cases

331 come from cement used in construction. In contrast, with mobility demand reduction through mode

332 shifting has a substantial mitigation potential and enables quicker near-term emission reductions

333 than for housing. With full electrification of public transport (LCT*), just from the combination

334 of higher occupancy and efficiency with electric public transit, emissions can be almost halved by

3352050 without any decarbonization, while providing the same level of mobility to all.
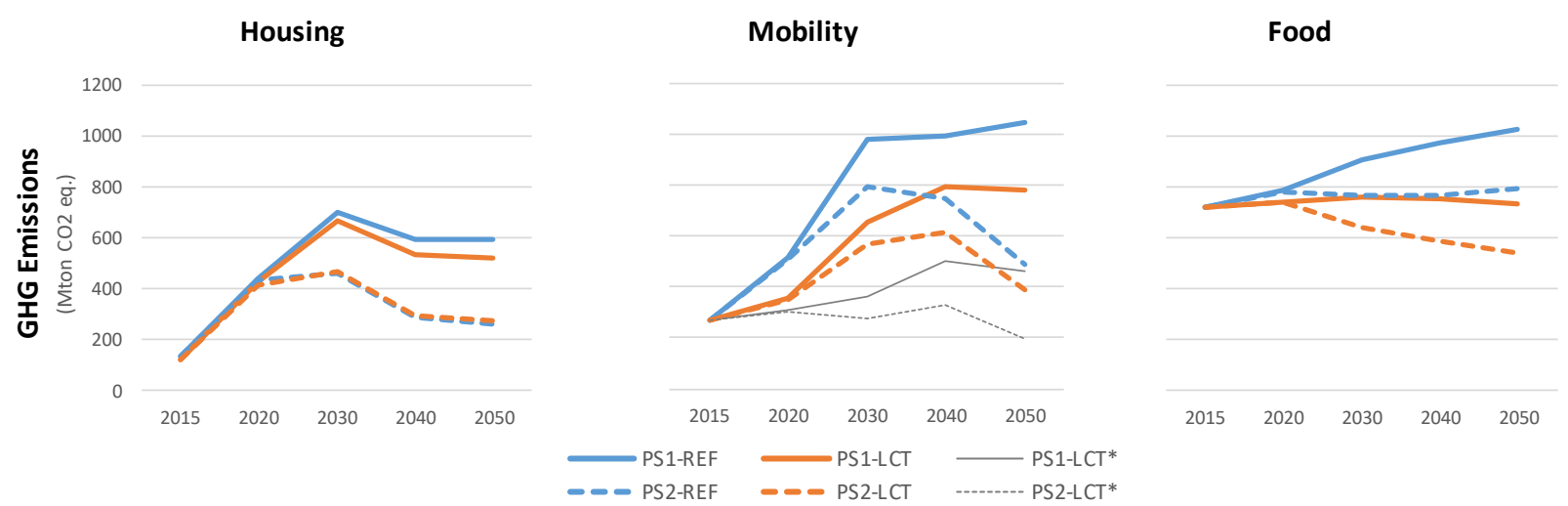

Figure 4. Emissions pathways for DLS scenarios for housing, mobility, and food in India. Demand side scenarios: reference (REF), low-carbon technologies (LCT), and low-carbon technology with public transport (bus) electrification (LCT*) by 2030. Supply-side scenarios:

342 current energy system (PS1) and $1.5^{\circ} \mathrm{C}$ (PS2).

\subsection{Recast of industrial energy demand}

345 The linkage of consumption to indirect final energy demand enables a broader picture of the

346 economy-wide energy and emissions reduction potential from changes in consumption, and

347 thereby a means to relate resource use directly to socioeconomic trends and material well-being.

348 This in turn enables a more comprehensive analysis of sustainable development pathways 
349 considering wellbeing and environmental impacts. Integrating IE methods and energy scenarios

350 allows recasting the industrial energy by the underlying driving services - rather than by sectors

351 - and further assess the impact of consumption changes and demand-side measures on energy and

352 environment. Our results for India show that providing basic services would require a considerable

353 amount of final embodied energy in 2015: 1.0 EJ for housing, 0.9 EJ for mobility, and 1.4 EJ for

354 food. One can compare these results with the current energy consumption for India ${ }^{64}$ and estimate

355 the share of total industrial final energy that would be needed to satisfy basic needs, i.e. $11 \%$ for

356 housing, $10 \%$ for mobility and $14 \%$ for food in 2015 . Such analyses can be extended to other types

357 of consumption, to characterize their economy-wide energy use. The linkage between service

358 demand and IAMs could also enable - through IE methods' other environmental impact

359 indicators - broader sustainability assessments that examine alongside climate mitigation goals

360 other objectives among the Sustainable Development Goals (SDG), such as sustainable

361 consumption and production, or even health and wellbeing-related goals, since consumption can

362 be linked to basic human needs. Furthermore, representing energy embodied in products and

363 services in final - rather than primary - terms, makes it possible to decouple material energy

364 requirements and future changes in the energy supply sector. With this flexibility, it is possible to

365 explicitly assess consumption-side, energy demand and supply-side measures in climate

366 stabilization pathways.

\subsection{Limitations and further research}

368 Some limitations apply regarding the data we used in LCA, representation of changes in the 369 manufacturing structure, and accounting of different types of fuel. 
370 For the LCA methods, we relied on data from internationally recognized databases to estimate the

371 ratio primary-to-final energy and the share of electricity. This might not completely reflect the

372 supply chains in the analyzed country, India, due to potentially different production processes.

373 However, country-specific life-cycle inventory data are mostly not available for developing

374 countries. Process-based LCA involves truncation errors as it depends on pre-defined system

375 boundaries ${ }^{65}$. The magnitude of such errors depends on the cut-off criteria and sector groups. Thus,

376 the comparability of LCA and EEIO results might be limited due to such issues as different system

377 boundaries and different treatment of capital inputs. To further ensure the direct comparability of

378 the results across demand categories, future research could examine the use of hybrid IO-LCA and

379 also compare with the results given in this work.

380 In our scenarios, we represent key technological and demand changes for housing, mobility and

381 food driven by targeted policies. Regarding future changes in manufacturing processes, our

382 analysis is limited to material efficiency improvements for building construction. A broader

383 representation of future changes in the manufacturing structure along different scenarios is

384 currently missing. With improved data availability and accounting of such changes in LCA-IO

385 methods ${ }^{66,67}$, structural and technological changes could be explicitly represented in the model.

386 In our methods we focused exclusively on the energy losses in the electric sector losses to

387 approximate the difference between primary and final energy. Future studies should further

388 characterize the efficiency losses in other fuel supply chains. Recasting of service-driven

389 demands for key industries, such as cement, steel, aluminum, pulp and paper, and petrochemical

390 is also suggested. This study presented a first step towards linking Industrial Ecology tools and

391 IAMs through a simplified methodology for decarbonization pathways. Future work should

392 focus on further integration with IAMs to improve the comparability of results across end-use 
393 services and upscaling for more comprehensive and economy-wide accounting of services, as

394 well as broader geographical coverage. This will enable the development of more robust and

395 comprehensive climate stabilization scenarios, including the evaluation of trade-offs between

396 material and technology use, energy demand and decarbonization options.

\section{Author Information}

398 Corresponding Author

399 * E-mail: mastrucc@iiasa.ac.at; Phone : +43 (0)2236 807296.

\section{Author Contribution}

401 Life Cycle Assessment methods: Alessio Mastrucci. Input-Output methods: Jihoon Min and

402 Arkaitz Usubiaga-Liaño. Scenarios development, results interpretation and paper writing:

403 Alessio Mastrucci, Jihoon Min, Narasimha D. Rao.

\section{Acknowledgments}

405 This work is made possible by the European Research Council Starting Grant [ERC-StG-2014, 406 No. 637462], for the project entitled: 'Decent Living Energy: energy and emissions thresholds 407 for providing decent living standards to all'.

\section{Associated Content}

409 Supporting Information. The following files are available free of charge.

410 Final energy accounts for Life Cycle Assessment and Input-Output, carbon emission intensities, 411 and description of the Decent Living Scenarios, including narratives, assumptions, detailed input 412 data, calculations and results. (PDF) 
414 (1) IPCC. Summary for Policymakers. Global Warming of $1.5^{\circ} \mathrm{C}$. In: An IPCC Special Report on the Impacts of Global Warming of $1.5^{\circ} \mathrm{C}$ above Pre-Industrial Levels and Related Global Greenhouse Gas Emission Pathways, in the Context of Strengthening the Global Response To. World Meteorological Organization: Geneva, Switzerland 2018.

(2) Waisman, H.; Mas, C.; Guerin, E. Pathways to Deep Decarbonization , a Problem Solving Approach for a $2^{\circ} \mathrm{C}$ Society. 2015, pp 1-3.

(3) Wilson, C.; Grubler, A.; Gallagher, K. S.; Nemet, G. F. Marginalization of End-Use Technologies in Energy Innovation for Climate Protection. Nat. Clim. Chang. 2012, 2 (11), 780-788. https://doi.org/10.1038/nclimate1576.

(4) Creutzig, F.; Roy, J.; Lamb, W. F.; Azevedo, I. M. L.; Bruin, W. B. De; Dalkmann, H.; Edelenbosch, O. Y.; Geels, F. W.; Grubler, A.; Hepburn, C.; Hertwich, E. G.; Khosla, R.; Mattauch, L.; Minx, J. C.; Ramakrishnan, A.; Rao, N. D.; Steinberger, J. K.; Tavoni, M.; Ürge-vorsatz, D.; Weber, E. U. Towards Demand-Side Solutions for Mitigating. Nat. Clim. Chang. 2018, 8 (April), 260-271. https://doi.org/10.1038/s41558-018-0121-1.

Grubler, A.; Wilson, C.; Bento, N.; Boza-Kiss, B.; Krey, V.; McCollum, D. L.; Rao, N. D.; Riahi, K.; Rogelj, J.; De Stercke, S.; Cullen, J.; Frank, S.; Fricko, O.; Guo, F.; Gidden, M.; Havlík, P.; Huppmann, D.; Kiesewetter, G.; Rafaj, P.; Schoepp, W.; Valin, H. A Low Energy Demand Scenario for Meeting the $1.5{ }^{\circ} \mathrm{C}$ Target and Sustainable Development Goals without Negative Emission Technologies. Nat. Energy 2018, 3 (6), 515-527. https://doi.org/10.1038/s41560-018-0172-6.

(6) Riahi, K.; Dentener, F.; Gielen, D.; Grubler, A.; Jewell, J.; Klimont, Z.; Krey, V.; McCollum, D.; Pachauri, S.; Rao, S.; van Ruijven, B.; van Vuuren, D. P.; Wilson, C. Chapter 17 - Energy Pathways for Sustainable Development. In Global Energy Assessment - Toward a Sustainable Future; Cambridge University Press, Cambridge, UK and New York, NY, USA and the International Institute for Applied Systems Analysis, Laxenburg, Austria, Cambridge, UK and New York, NY, USA and the International Institute for Applied Systems Analysis, Laxenburg, Austria, 2012; pp 1203-1306.

Moberg, K. R.; Aall, C.; Dorner, F.; Reimerson, E.; Ceron, J. P.; Sköld, B.; Sovacool, B. K.; Piana, V. Mobility, Food and Housing: Responsibility, Individual Consumption and Demand-Side Policies in European Deep Decarbonisation Pathways. Energy Effic. 2019, 12 (2), 497-519. https://doi.org/10.1007/s12053-018-9708-7.

(8) Arvesen, A.; Luderer, G.; Pehl, M.; Bodirsky, B. L.; Hertwich, E. G. Deriving Life Cycle Assessment Coefficients for Application in Integrated Assessment Modelling. Environ. Model. Softw. 2018, 99, 111-125. https://doi.org/10.1016/j.envsoft.2017.09.010.

(9) Ortiz, O.; Castells, F.; Sonnemann, G. Sustainability in the Construction Industry: A Review of Recent Developments Based on LCA. Constr. Build. Mater. 2009, 23 (1), 28-39. https://doi.org/10.1016/j.conbuildmat.2007.11.012. 
(10) Pauliuk, S.; Arvesen, A.; Stadler, K.; Hertwich, E. G. Industrial Ecology in Integrated Assessment Models. Nat. Publ. Gr. 2017, 7 (1), 13-20. https://doi.org/10.1038/nclimate3148.

(11) Volkart, K.; Mutel, C. L.; Panos, E. Integrating Life Cycle Assessment and Energy System Modelling: Methodology and Application to the World Energy Scenarios. Sustain. Prod. Consum. 2018, 16, 121-133. https://doi.org/10.1016/j.spc.2018.07.001.

(12) Gibon, T.; Arvesen, A.; Hertwich, E. G. Life Cycle Assessment Demonstrates Environmental Co-Bene Fi Ts and Trade- o Ff s of Low-Carbon Electricity Supply Options. Renew. Sustain. Energy Rev. 2017, 76 (November 2016), 1283-1290. https://doi.org/10.1016/j.rser.2017.03.078.

(13) Hertwich, E. G.; Gibon, T.; Bouman, E. A.; Arvesen, A.; Suh, S.; Heath, G. A. Integrated Life-Cycle Assessment of Electricity-Supply Scenarios Confirms Global Environmental Benefit of Low-Carbon Technologies. Proc. Natl. Acad. Sci. 2015, 112 (20). https://doi.org/10.1073/pnas.1312753111.

(14) Hellweg, S.; Canals, L. M. i. Emerging Approaches, Challenges and Opportunities in Life Cycle Assessment. Science (80-. ). 2014, 344 (6188), 1109-1114. https://doi.org/10.1126/science.1248361.

(15) Pauliuk, S.; Sjöstrand, K.; Müller, D. B. Transforming the Norwegian Dwelling Stock to Reach the 2 Degrees Celsius Climate Target. J. Ind. Ecol. 2013, 17 (4), 542-554. https://doi.org/10.1111/j.1530-9290.2012.00571.x.

(16) Mastrucci, A.; Marvuglia, A.; Leopold, U.; Benetto, E. Life Cycle Assessment of Building Stocks from Urban to Transnational Scales: A Review. Renew. Sustain. Energy Rev. 2017, 74. https://doi.org/10.1016/j.rser.2017.02.060.

(17) Usón, A. A.; Capilla, A. V.; Bribián, I. Z.; Scarpellini, S.; Sastresa, E. L. Energy Efficiency in Transport and Mobility from an Eco-Efficiency Viewpoint. Energy 2011, 36, 1916-1923. https://doi.org/10.1016/j.energy.2010.05.002.

(18) Mcdowall, W.; Solano, B.; Usubiaga, A. Is the Optimal Decarbonization Pathway in Fl Uenced by Indirect Emissions? Incorporating Indirect Life-Cycle Carbon Dioxide Emissions into a European TIMES Model Jos E. 2018, 170, 260-268. https://doi.org/10.1016/j.jclepro.2017.09.132.

(19) Brand, C.; Tran, M.; Anable, J. The UK Transport Carbon Model : An Integrated Life Cycle Approach to Explore Low Carbon Futures. Energy Policy 2012, 41, 107-124. https://doi.org/10.1016/j.enpol.2010.08.019.

(20) Bergesen, J. D.; Leena, T. Potential Long-Term Global Environmental Implications of Efficient Light-Source Technologies. 2015, $20 \quad$ (2), 263-275. https://doi.org/10.1111/jiec.12342.

(21) Beucker, S.; Bergesen, J. D.; Gibon, T. Building Energy Management Systems: Global 
Potentials and Environmental Implications of Deployment. J. Ind. Ecol. 2016, 20 (2), 223233. https://doi.org/10.1111/jiec.12378.

(22) Lenzen, M.; Wier, M.; Cohen, C.; Hayami, H.; Pachauri, S.; Schaeffer, R. A Comparative Multivariate Analysis of Household Energy Requirements in Australia, Brazil, Denmark, India and Japan. Energy 2006, $31 \quad(2-3), \quad$ 181-207. https://doi.org/10.1016/j.energy.2005.01.009.

(23) Minx, J.; Baiocchi, G.; Wiedmann, T.; Barrett, J.; Creutzig, F.; Feng, K.; Förster, M.; Pichler, P.-P.; Weisz, H.; Hubacek, K. Carbon Footprints of Cities and Other Human Settlements in the UK. Environ. Res. Lett. 2013, 8 (3), 35039. https://doi.org/10.1088/17489326/8/3/035039.

(24) Park, H.-C.; Heo, E. The Direct and Indirect Household Energy Requirements in the Republic of Korea from 1980 to 2000-An Input-Output Analysis. Energy Policy 2007, 35 (5), 2839-2851. https://doi.org/10.1016/j.enpol.2006.10.002.

(25) Liu, Z.; Geng, Y.; Lindner, S.; Zhao, H.; Fujita, T.; Guan, D. Embodied Energy Use in China's Industrial Sectors. Energy Policy 2012, 49, 751-758. https://doi.org/10.1016/j.enpol.2012.07.016.

(26) Wei, Y.-M.; Liu, L.-C.; Fan, Y.; Wu, G. The Impact of Lifestyle on Energy Use and CO2 Emission: An Empirical Analysis of China's Residents. Energy Policy 2007, 35 (1), 247257. https://doi.org/10.1016/j.enpol.2005.11.020.

(27) Owen, A.; Brockway, P.; Brand-correa, L.; Bunse, L.; Sakai, M.; Barrett, J. Energy Consumption-Based Accounts: A Comparison of Results Using Different Energy Extension Vectors. Appl. Energy 2017, 190, 464-473. https://doi.org/10.1016/j.apenergy.2016.12.089.

(28) Wiebe, K. S.; Bjelle, E. L.; Többen, J.; Wood, R. Implementing Exogenous Scenarios in a Global MRIO Model for the Estimation of Future Environmental Footprints. J. Econ. Struct. 2018, 7 (20). https://doi.org/10.1186/s40008-018-0118-y.

(29) Koning, A. De; Huppes, G.; Deetman, S.; Tukker, A. Scenarios for a $2^{\circ} \mathrm{C}$ World : A TradeLinked Input - Output Model with High Sector Detail Scenarios for a $28 \mathrm{C}$ World : A Trade-Linked Input - Output Model with High Sector Detail. Clim. Policy 2016, 16 (3), 301-317. https://doi.org/10.1080/14693062.2014.999224.

(30) Rao, N. D.; Min, J.; Mastrucci, A. Energy Requirements for Decent Living in India, Brazil and South Africa. Nat. Energy 2019. https://doi.org/10.1038/s41560-019-0497-9.

(31) Rao, N. D.; Min, J. Decent Living Standards: Material Prerequisites for Human Wellbeing. Soc. Indic. Res. 2017, 138 (1), 225-244. https://doi.org/10.1007/s11205-017-1650-0.

(32) Rao, N. D.; Baer, P. "Decent Living” Emissions: A Conceptual Framework. Sustainability 2012, 4 (4), 656-681. https://doi.org/10.3390/su4040656. 
(33) Mastrucci, A.; Rao, N. D. Decent Housing in the Developing World: Reducing Life-Cycle Energy Requirements. Energy Build. 152. https://doi.org/10.1016/j.enbuild.2017.07.072.

(34) Rao, N. D.; Min, J.; DeFries, R.; Ghosh-Jerath, S.; Valin, H.; Fanzo, J. Healthy, Affordable and Climate-Friendly Diets in India. Glob. Environ. Chang. 2018, 49, 154-165. https://doi.org/10.1016/j.gloenvcha.2018.02.013.

(35) Pehl, M.; Arvesen, A.; Humpenöder, F.; Popp, A.; Hertwich, E. G.; Luderer, G. Understanding Future Emissions from Low-Carbon Power Systems by Integration of LifeCycle Assessment and Integrated Energy Modelling. Nat. Energy 2017, 2 (12), 939-945. https://doi.org/10.1038/s41560-017-0032-9.

(36) Blok, K.; Nieuwlaar, E. Introduction to Energy Analysis, Second Edi.; Routledge, Ed.; London and New York.

(37) Suh, S.; Huppes, G. Methods for Life Cycle Inventory of a Product. J. Clean. Prod. 2005, 13, 687-697. https://doi.org/10.1016/j.jclepro.2003.04.001.

(38) VDI-Richtlinien. Cumulative Energy Demand - Terms, Definitions, Methods of Calculation. VDI - Guideline 4600; Beuth Verlag GmbH, Berlin, 1997.

(39) Mutel, C. Brightway: An Open Source Framework for Life Cycle Assessment. 2017, 47 (11), 11-12. https://doi.org/10.21105/joss.00236.

(40) Wernet, G.; Bauer, C.; Steubing, B.; Reinhard, J.; Moreno-Ruiz, E.; Weidema, B. The Ecoinvent Database Version 3 (Part I): Overview and Methodology. Int. J. Life Cycle Assess. 2016, 21 (9), 1218-1230. https://doi.org/10.1007/s11367-016-1087-8.

(41) Miller, R. E.; Blair, P. D. Input-Output Analysis: Foundations and Extensions; Cambridge University Press, 2009.

(42) United Nations (UN). System of Environmental-Economic Accounting 2012 - Central Framework; European Commission, FAO, IMF, OECD, UN, the World Bank, United Nations: New York, 2014.

(43) Stadler, K.; Wood, R.; Kuenen, J.; Bruckner, M.; Giljum, S.; Lutter, S.; Merciai, S.; Konstantin, S.; Richard, W.; Tatyana, B.; Carl-Johan, S.; Moana, S.; Sarah, S.; Arkaitz, U.; José, A.; Jeroen, K.; Martin, B.; Stefan, G.; Stephan, L.; Stefano, M.; H., S. J.; C., T. M.; Christoph, P.; Thomas, K.; Nina, E.; Karl-Heinz, E.; Arjan, K.; Arnold, T. EXIOBASE 3: Developing a Time Series of Detailed Environmentally Extended Multi-Regional InputOutput Tables. J. Ind. Ecol. 2018, 22 (3), 502-515. https://doi.org/10.1111/jiec.12715.

(44) Usubiaga-Liaño, A., Behrens, P. and Daioglou, V. Energy Use in the Global Food System. J. Ind. Ecol. Accepted.

(45) International Energy Agency (IEA). Energy Balances of Non-OECD Countries (2016 Edition); Paris, 2017. 
(46) International Energy Agency (IEA). Energy Balances of OECD Countries (2016 Edition); Paris, 2017.

(47) Usubiaga, A.; Acosta-fernández, J. Carbon Emission Accounting in MRIO Models: The Territory Vs. the Residence Principle. Econ. Syst. Res. 2015, 27 (4), 458-477. https://doi.org/10.1080/09535314.2015.1049126.

(48) Min, J.; Rao, N. D. Estimating Uncertainty in Household Energy Footprints. J. Ind. Ecol. 2017. https://doi.org/10.1111/jiec.12670.

(49) Riahi, K.; Vuuren, D. P. Van; Kriegler, E.; Edmonds, J.; Neill, B. C. O.; Fujimori, S.; Bauer, N.; Calvin, K.; Dellink, R.; Fricko, O.; Lutz, W.; Popp, A.; Crespo, J.; Kc, S.; Leimbach, M.; Jiang, L.; Kram, T.; Rao, S.; Emmerling, J.; Ebi, K.; Hasegawa, T.; Havlik, P.; Humpenöder, F.; Aleluia, L.; Silva, D.; Smith, S.; Stehfest, E.; Bosetti, V.; Eom, J.; Gernaat, D.; Masui, T.; Rogelj, J.; Stre, J.; Drouet, L.; Krey, V.; Luderer, G.; Harmsen, M.; Takahashi, K.; Baumstark, L.; Doelman, J. C.; Kainuma, M.; Klimont, Z.; Marangoni, G.; Lotze-campen, H.; Obersteiner, M.; Tabeau, A.; Tavoni, M. The Shared Socioeconomic Pathways and Their Energy, Land Use, and Greenhouse Gas Emissions Implications : An Overview. 2017, 42, 153-168. https://doi.org/10.1016/j.gloenvcha.2016.05.009.

(50) McCollum, D. L.; Zhou, W.; Bertram, C.; de Boer, H.-S.; Bosetti, V.; Busch, S.; Després, J.; Drouet, L.; Emmerling, J.; Fay, M.; Fricko, O.; Fujimori, S.; Gidden, M.; Harmsen, M.; Huppmann, D.; Iyer, G.; Krey, V.; Kriegler, E.; Nicolas, C.; Pachauri, S.; Parkinson, S.; Poblete-Cazenave, M.; Rafaj, P.; Rao, N.; Rozenberg, J.; Schmitz, A.; Schoepp, W.; van Vuuren, D.; Riahi, K. Energy Investment Needs for Fulfilling the Paris Agreement and Achieving the Sustainable Development Goals. Nat. Energy 2018, 1. https://doi.org/10.1038/s41560-018-0179-z.

(51) Mastrucci, A.; Rao, N. D. Bridging India's Housing Gap: Lowering Costs and CO2 Emissions. Build. Res. Inf. 2019, 47 (1), 8-23. https://doi.org/10.1080/09613218.2018.1483634.

(52) Ramesh, T.; Prakash, R.; Kumar Shukla, K. Life Cycle Energy Analysis of a Multifamily Residential House: A Case Study in Indian Context. Open J. Energy Effic. 2013, 02 (01), 34-41. https://doi.org/10.4236/ojee.2013.21006.

(53) Ramesh, T.; Prakash, R.; Shukla, K. K. Life Cycle Energy Analysis of a Residential Building with Different Envelopes and Climates in Indian Context. Appl. Energy 2012, 89 (1), 193-202. https://doi.org/10.1016/j.apenergy.2011.05.054.

(54) Bansal, D.; Singh, R.; Sawhney, R. L. Effect of Construction Materials on Embodied Energy and Cost of Buildings - A Case Study of Residential Houses in India up to 60 M2 of Plinth Area. Energy Build. 2014, 69, 260-266. https://doi.org/10.1016/j.enbuild.2013.11.006.

(55) Praseeda, K. I.; Reddy, B. V. V.; Mani, M. Embodied and Operational Energy of Urban Residential Buildings in India. Energy Build. 2016, 110, 211-219. https://doi.org/10.1016/j.enbuild.2015.09.072. 
(56) Tiwari, P.; Rao, J.; Day, J. Housing Development in a Developing India. In Development Paradigms for Urban Housing in BRICS Countries,; 2016. https://doi.org/10.1057/978-1137-44610-7.

(57) Chastas, P.; Theodosiou, T.; Bikas, D. Embodied Energy in Residential Buildings-towards the Nearly Zero Energy Building: A Literature Review. Build. Environ. 2016, 105, 267282. https://doi.org/10.1016/j.buildenv.2016.05.040.

(58) Praseeda, K. I.; Mani, M.; Venkatarama Reddy, B. V. Assessing Impact of Material Transition and Thermal Comfort Models on Embodied and Operational Energy in Vernacular Dwellings (India). Energy Procedia 2014, 54, 342-351. https://doi.org/10.1016/j.egypro.2014.07.277.

(59) Schafer, A. Regularities in Travel Demand: An International Perspective Massachusetts Institute of Technology. J. Transp. Stat. 2000, 3 (3), 1-32.

(60) Ahmad, S.; Creutzig, F. Spatially Contextualized Analysis of Energy Use for Commuting in India. Environ. Res. Lett. 2019, 14 (4). https://doi.org/10.1088/1748-9326/ab011f.

(61) Tiwari, G.; Kumar, A.; Bhandari, K. Comparing Impact of Public Transport Systems ( Bus vs . Metro Rail ) Based on Life Cycle Assessment Method : Delhi, India.

(62) Valin, H.; Sands, R. D.; Mensbrugghe, D. Van Der; Nelson, G. C.; Ahammad, H.; Blanc, E.; Bodirsky, B.; Fujimori, S.; Hasegawa, T.; Havlik, P.; Meijl, H. Van; Lampe, M. Von; Willenbockel, D. The Future of Food Demand: Understanding Differences in Global Economic Models. 2014, 45, 51-67. https://doi.org/10.1111/agec.12089.

(63) Rao, N. D.; Poblete-cazenave, M.; Bhalerao, R.; Davis, K. F.; Parkinson, S. Spatial Analysis of Energy Use and GHG Emissions from Cereal Production in India. Sci. Total Environ. 2019, 654, 841-849. https://doi.org/10.1016/j.scitotenv.2018.11.073.

(64) International Energy Agency (IEA). Sankey Diagram. India, Final consumption (2015) https://www.iea.org/sankey/.

(65) Ward, H. Truncation Error Estimates in Process Life Cycle Assessment Using Input-Output Analysis. J. Ind. Ecol. 2017, 22 (5), 1080-1091. https://doi.org/10.1111/jiec.12655.

(66) Arvidsson, R.; Janssen, M.; Nordel, A. Environmental Assessment of Emerging Technologies Recommendations for Prospective LCA. J. Ind. Ecol. 2017, 22 (6), 12861294. https://doi.org/10.1111/jiec.12690.

(67) Wiebe, K. S.; Bjelle, E. L.; Többen, J.; Wood, R. Implementing Exogenous Scenarios in a Global MRIO Model for the Estimation of Future Environmental Footprints. J. Econ. Struct. 2018, 7 (20). https://doi.org/10.1186/s40008-018-0118-y. 